demand and low decision-making latitude), iso-strain (job-strain and lack of social support), and low-strain (relaxed or low-load work).

Results: Among the 261 participants in the study, $67.43 \%$ were women. The average age was $39.80 \pm 9.4$ years. The average length of professional service was $8.91 \pm 7.30$ years [ 1 - 35 years].

Regarding the job stress, $65.14 \%$ of the healthcare workers followed at least 11 patients per day. $78.54 \%$ had more than 40 hours of weekly work and $46.36 \%$ carried heavy loads during work. Job-strain was found in $58.62 \%$ of the participants, iso-strain in $7.66 \%$ and low-strain in $5.36 \%$. MSDs were described by 225 participants $(86.21 \%)$. They were mainly low back pain $(68.44 \%)$, neck pain $(52 \%)$ and shoulders' pain $(37.78 \%)$.

In multivariate analysis, only weekly work> 40 hours (OR $=2.59 ; 95 \% \mathrm{Cl}$ $1.11-6.02, p=0.026)$ and job-strain $(\mathrm{OR}=3.14 ; 95 \% \mathrm{Cl} 1.33-7.39, \mathrm{p}=0.009)$ remained associated with the presence of MSD.

Conclusion: The healthcare workers in our study are exposed to a high psychological and physical job stress, causing MSDs. Ergonomic programs should be designed for these workers.

Disclosure of Interests: None declared

DOI: 10.1136/annrheumdis-2020-eular.5857

\section{AB0966 PREVALENCE OF SARCOPENIA IN PATIENTS WITH RHEUMATOLOGICAL DISEASES}

Y. Lavrishcheva ${ }^{1}$, A. Jakovenko ${ }^{2}{ }^{1} 1$ Almazov National Medical Research Centre, Saint Petersburg, Russian Federation, Saint Petersburg, Russian Federation; ${ }^{2}$ Pavlov First Saint Petersburg State Medical University, Saint Petersburg, Russian Federation, Saint Petersburg, Russian Federation

Background: The presence of sarcopenia in rheumatological patients is an independent predictor of morbidity and mortality in this cohort of patients. Patients with sarcopenia are characterized by lower physical activity, a tendency to depression and poor social adaptation.

Objectives: To assess the prevalence of sarcopenia in rheumatological patients. Methods: 317 patients were examined, including 79 with systemic lupus erythematosus, 98 with rheumatoid arthritis, 72 with systemic scleroderma, 68 with spondyloarthritis. Among them, 201 women and 116 men, the age of patients ranged from 21 to 58 years, the average age at the time of inclusion of patients in the study was $41.1 \pm 7.3$ years. Sarcopenia was diagnosed using the method recommended by The European Working Group on Sarcopenia in Older People2.

Results: The frequency of occurrence of a decrease in the total mass of skeletal muscle according to the skeletal muscle mass index (ISMM) was 31.2\% (99 patients), a decrease in muscle strength according to the wrist dynamometry was observed in $44.5 \%$ (141 patients), low skeletal muscle performance according to the results $\mathrm{NIH}$ Toolbox 4 Meter Walk Gait Speed Test in 42.8\% (135 patients). The prevalence of suspected sarcopenia (probable sarcopenia) was 13.3\% (42 patients) and sarcopenia 31.2\% (99 patients), no cases of severe sarcopenia were detected. Statistically significant differences were obtained between groups of patients depending on the duration of rheumatological disease and the prevalence of sarcopenia $(x 2=19.328 p=0.001)$.

Conclusion: The prevalence of sarcopenia in rheumatological patients in the general population was $31.2 \%$.

Disclosure of Interests: None declared

DOI: 10.1136/annrheumdis-2020-eular.1885

\section{AB0967 $\quad$ OBESITY IMPACTS SURGICAL REPAIR OF ROTATOR CUFF TEAR IN A LOW-INCOME POPULATION}

C. Silva ${ }^{1}$, N. Mourão ${ }^{1}$, J. Landim², L. Da Rocha ${ }^{2}$, M. Lacerda ${ }^{1}$, A. Rocha ${ }^{2} .{ }^{1}$ Hospital Geral De Fortaleza, Fortaleza, Brazil; ${ }^{2}$ Faculty of Medicine - Federal University of Ceará, Internal Medicine, Fortaleza, Brazil

Background: Rotator cuff tears (RCT) rank high among causes of shoulder pain in primary care. Surgical repair of RCT is indicated when judged refractory to clinical treatment. Comorbidities and environmental issues may impact the surgical result of $\mathrm{RCT}$ repair.

Objectives: to determine the impact of Obesity and Smoking in the outcome of low-income patients subjected to RCT repair.

Methods: Low-income ( $<5500,00$ US\$ annual pib per capta*) patients living in Fortaleza-CE, Brazil were prospectively (2016-2018) evaluated in the Orthopedic and Rheumatology Services of the Hospital Geral de Fortaleza. Demographics and clinical data focusing Obesity (BMI $>/ \leq 30$ ) and Smoking status (present/absent) were registered. Pain $(0-10 \mathrm{~cm}$ VAS) and functional shoulder score evaluation by the University of California at Los Angeles Shoulder Score (UCLA) and American Shoulder and Elbow Surgeons (ASES) scoring systems following at least 2 years post-operative follow-up were recorded.

Results: Thirty-nine individuals, $60.9 \pm 7.1$ years-old, 30 female $(68.3 \%)$ with $5.1 \pm 1.9$ years follow-up were evaluated; $21(44.7 \%)$ were Smokers and $12(25.5 \%)$ Obese $(\mathrm{BMI}>30)$. Other comorbidities included 16 arterial hypertension, 18 dyslipidemia, 17 osteoarthritis, 4 rheumatoid arthritis, 1 gout. Pain VAS values were $5.1 \pm 2.6$ vs $3.1 \pm 2.8$ in Obese vs Non-Obese $(p=0.03)$ and $4 \pm 2.8$ vs $3.37 \pm 2.99$ in Smokers vs Non-Smokers ( $p=0.26$ ), respectively. UCLA was $22.4 \pm 8.2$ vs. $28.79 \pm 5.6$ in
Obese vs Non-Obese $(p=0.004)$ and $26.2 \pm 6.5$ vs. $27.75 \pm 7.18(p=0.25)$ in Smokers vs. Non-smokers, respectively. ASES was $47.89 \pm 28.3$ vs. $68.1 \pm 25.78(p=0.021)$ in Obese vs. Non-obese and $58.98 \pm 26.69$ vs $65.3 \pm 28.1 \quad(p=0.243)$ in Smokers vs Non-Smokers, respectively.

Conclusion: Using Patient Reported Outcome instruments, these long-term data show that Obesity negatively impacts the outcome of surgical repair of RCT in low-income patients. Smoking status was apparently irrelevant but the number of cigarettes smoked daily was not considered. Emphasis on weight reduction is a practical, affordable though hard to implement measure that could improve surgical results when repairing RCT.

References: *https://pt.wikipedia.org/wiki/Lista_de_munic\%C3\%ADpios_do Brasil_por_PIB

Disclosure of Interests: Christine Silva: None declared, Natalia Mourão: None declared, Joaquim Landim: None declared, Leila da Rocha: None declared, Marco Lacerda: None declared, Airton Rocha Speakers bureau: Not related to the present work

DOI: 10.1136/annrheumdis-2020-eular.3128

AB0968

DIAGNOSIS OF INFLAMMATORY BACK PAIN (IBP) IN A LOW-INCOME POPULATION USING ASAS IBP DEFINITION

J. Oliveira ${ }^{1}$, R. Nunes ${ }^{1}$, G. Da Silva ${ }^{1}$, I. Nogueira ${ }^{1}$, A. Azevedo ${ }^{1}$, X. Baraliakos ${ }^{2}$, A. Rocha ${ }^{1}$. ${ }^{1}$ Faculty of Medicine - Federal University of Ceará, Fortaleza, Brazil; ${ }^{2}$ Rheumazentrum Ruhrgebiet, Herne, Berlin, Germany

Background: Inflammatory back pain (IBP) is an important entry criterion for identify ing patients with axial spondyloarthritis. Due to the very frequent prevalence of chronic non-inflammatory back pain (CBP), IBP is difficult to differentiate and recognize in many clinical practices. CBP is a frequent diagnosis in populations with low socioeconomic status.

Objectives: To investigate whether IBP ASAS definition help discriminate from CBP in a low-income population.

Methods: A total of 202 consecutive individuals were directly interviewed in Fortaleza/ Brazil, for the prevalence of IBP (ASAS definition), monthly family income (US\$), school education $[>/ \leq 8$ school-years(SY)], and smoking habit (present/absent). People from all social levels were included.

Results: Mean age was $38.9 \pm 12.9$ years, 100 (49.5\%) were male and $36(17.8 \%)$ were smokers; $135(66.8 \%)$ declared less than 730 US\$ family earnings per month and $71(35.1 \%)$ had less than 8 SY. Although 122 (60.3\%) declared lumbar pain, in comparison, 29 (14.3\%), 22 (10.9\%) and 59 (29.2\%) fulfilled ASAS, Berlin, and Calin's IBP criteria, respectively. There were $39(58.02 \%)$ vs. $83(61.5 \%)$ with vs. without CBP and $9(13.4 \%)$ vs. 20 (14.8\%) fulfilling vs. not fulfilling the ASAS IBP definition among those with more or less than 730US $\$$ earnings $(P>0.05)$, respectively.

Conclusion: This is the first report on the prevalence of IBP in a very low-income population. Over one-third had less than $8 S Y$, revealing very low literacy. Smoking prevalence was also low if compared to $28 \%$ smoking prevalence WHO estimates across Europe*. These IBP prevalence data are similar to those reported in wealthier populations, living in higher latitude. Data suggest that ASAS IBP definition may be used to discriminate patients with IBP from those with CBP, regardless of income and literacy. References: This is the first report on the prevalence of IBP in a very low-income population. Over one-third had less than 8SY, revealing very low literacy. Smoking prevalence $(17.8 \%$ ) was also low if compared to $28 \%$ smoking prevalence WHO estimates across Europe*. These IBP prevalence data are similar to those reported in wealthier populations, living in higher latitude. Data suggest that ASAS IBP definition may be used to discriminate patients with IBP from those with CBP, regardless of income and literacy.

Disclosure of Interests: Jobson Oliveira: None declared, Rodolfo Nunes: None declared, Guilherme da Silva: None declared, Igor Nogueira: None declared, Artur Azevedo: None declared, Xenofon Baraliakos Grant/research support from: Grant/ research support from: AbbVie, BMS, Celgene, Chugai, Merck, Novartis, Pfizer, UCB and Werfen, Consultant of: AbbVie, BMS, Celgene, Chugai, Merck, Novartis, Pfizer, UCB and Werfen, Speakers bureau: AbbVie, BMS, Celgene, Chugai, Merck, Novartis Pfizer, UCB and Werfen, Airton Rocha Speakers bureau: Not related to the present work

DOI: 10.1136/annrheumdis-2020-eular.4260

\section{AB0969}

GAINED WEIGHT DURING PREGNANCY AND LOW BACK PAIN: IS IT REALLY ASSOCIATED?

M. Yasmine ${ }^{1}$, S. Miladi ${ }^{1}$, A. Fazaa ${ }^{1}$, L. Souebni ${ }^{1}$, S. Mariem ${ }^{1}$, K. Ouenniche ${ }^{1}$ S. Kassab ${ }^{1}$, S. Chekili ${ }^{1}$, K. Ben Abdelghani ${ }^{1}$, A. Laatar ${ }^{1} .{ }^{1}$ Mongi Slim Hospital, Tunis, Tunisia

Background: Back pain is known to be a common complaint during pregnancy explained by gained weight in this period. Besides, the incidence of low back pain (LBP) in postpartum has also been quoted to be non-negligible even after delivery.

Objectives: The aim of our study was to assess if the development of LBP during the post-partum period was correlated to gained weight after delivery. 
Methods: In this prospective study, we assessed a survey of 60 women under the age of 35 for back pain symptoms during the postpartum period from day 1 to 18 months. A structured questionnaire using Google form was used. Data from this survey were then correlated with gained weight and pregnancy outcome, as well as women's history of LBP.

Results: We interviewed 60 women during their post-partum period. The mean age was 27,9 years old [24, 35 years]. Women were on average at 9 months of post-partum [1, 18 months]. The median height was 1,6 meters [1,54-1,74m]. The median weight at the moment of the study was 63,2 kilograms [48-80kg]. Before pregnancy, body mass index was $23,5 \mathrm{Kg} / \mathrm{m}^{2}\left[17-34 \mathrm{Kg} / \mathrm{m}^{2}\right]$. The total gained weight at the end of pregnancy was $14 \mathrm{~kg}$ [12-29 kg]. Only $20 \%$ gained more than $15 \mathrm{~kg}$. LBP was experienced in $35 \%$ of cases with a mean delay of 3,2 months post-partum [1-8 months]. The prevalence of persistent LBP was noted in $26 \%$ of cases. However, no correlation was found between LBP and gained weight $(p=0,07)$. Sixty five percent reported one or more significant episodes of back pain during their pregnancy. Significantly, more patients suffering from pain in pregnancy had history of previous back pain episodes when not pregnant $(p<0,001)$, as well as during previous pregnancies $(p<0,001)$.

Conclusion: No correlation was found between gained weight and occurrence of LBP. The main factors associated with the development of back pain were previous episodes of back pain while non-pregnant or pregnant.

Disclosure of Interests: None declared

DOI: 10.1136/annrheumdis-2020-eular.334

\section{Paediatric rheumatology}

\section{AB0970 STRUCTURAL MALFORMATIONS, DISC-VERTEBRA DEGENERATION AND DISC HERNIATION IN THE PEDIATRIC AGE GROUP}

O. G. Illeez ${ }^{1}$, F. E. Bahadir Ulger ${ }^{2}$, I. Aktas ${ }^{1} .{ }^{1}$ Fatih Sultan Mehmet Training and Research Hospital, Physical Medicine and Rehabilitation, Istanbul, Turkey; ${ }^{2}$ Fatih Sultan Mehmet Training and Research Hospital, Radiology, Istanbul, Turkey

Background: Disc/vertebral degeneration and disc herniation are rare causes of low back pain in childhood. Their relationship with congenital anomalies were reviewed in few studies in literature (1-3).

Objectives: To examine the relation between congenital structural malformations in the lumbar spine, early degeneration and lumbar disc herniation in pediatric age group patients with low back pain, and to determine the incidence of congenital structural malformations, disc/vertebral degeneration, and disc herniation. Methods: Four hundred patients with LBP persisting for at least six weeks were included in the study. Demographic characteristics, physical examination findings, and laboratory and imaging results were recorded for all patients. Severity of pain was determined using a visual analog scale (VAS). Lumbosacral X-rays were examined for the presence of lumbosacral transitional vertebrae (LSTV) and spina bifida occulta (SBO). The incidence of disc/vertebral degeneration and disc herniation was investigated at the L4-5 and L5-S1 level in lumbosacral magnetic resonans imaging of patients with and without congenital malformation (LSTV-SBO). Results: The study population consisted of 219 girls and 181 boys aged 10-17 years (mean age $14.9 \pm 1.9$ ). Presentation symptoms were low back pain in $90.5 \%$ $(n=362)$, and low back-leg pain in $9.5 \%(n=38)$. The mean VAS score was $5.3 \pm 1.0$. LSTV was determined in $67(16.8 \%)$ patients and SBO in $62(15.5 \%)$. Disc herniation was determined in 68 patients, at the L4-5 level in $26.5 \%(n=18)$, at the L5-S1 level in $48.5 \%(n=33)$, and at both levels in $25 \%(n=17)$. Vertebral degeneration was present at the L4-5 level in $14(8.6 \%)$ patients and at the L5-S1 level in $39(23.9 \%)$, while disc degeneration was present at the L4-5 level in 21 $(12.8 \%)$ patients and at the L5-S1 level in $31(19.0 \%)$. No significant difference was observed in the incidence of disc/vertebral degeneration and disc herniation in patients with congenital malformation. Disc herniation was significantly more common in patients with disc degeneration $(p=0.003, p<0.001)$. Congenital malformations were not observed in approximately $80 \%$ of patients without disc herniation and disc/vertebral degeneration.

Conclusion: The presence of congenital malformations does not appear to represent a risk factor for early degeneration and disc herniation in pediatric age group. Congenital malformations, early degeneration, and disc herniation may constitute an underlying pathology in pediatric patients with persistent low back pain.

References:

[1] Milicić G, et al. Causal connection of non-specific low back pain and disc degeneration in children with transitional vertebra and/or Spina bifida occulta: role of magnetic resonance--prospective study. Coll Antropol. 2012.

[2] Dang L, et al. Lumbar Disk Herniation in Children and Adolescents: The Significance of Configurations of the Lumbar Spine. Neurosurgery. 2015.
[3] Zhang B, et al. Lumbosacral Transitional Vertebra: Possible Role inthe Pathogenesis of Adolescent Lumbar Disc Herniation. World Neurosurg. 2017.

Disclosure of Interests: None declared DOI: 10.1136/annrheumdis-2020-eular.558

\section{AB0971 LONG-TERM EFFICACY AND SAFETY OF CANAKINUMAB IN PATIENTS WITH SYSTEMIC JUVENILE IDIOPATHIC ARTHRITIS: RESULTS FROM A SINGLE-CENTER STUDY}

E. Alexeeva $^{1,2}$, E. Krekhova $^{2}$, T. Dvoryakovskaya ${ }^{1,2}$, K. Isaeva $^{1}$, A. Chomakhidze ${ }^{1}$, E. Chistyakova ${ }^{1,2}$, O. Lomakina ${ }^{1}$, R. Denisova ${ }^{1}$, A. Mamutova ${ }^{1}$, A. Fetisova ${ }^{1}$, M. Gautier ${ }^{1}$, D. Vankova ${ }^{1}$, M. Shingarova ${ }^{2}$, I. Kriulin ${ }^{1,2}$, A. Alshevskaya ${ }^{3}$, A. Moskalev ${ }^{3} .{ }^{1}$ National Medical Research Center of Children's Health, Moscow, Russian Federation; ${ }^{2}$ Sechenov First Moscow State Medical University (Sechenov University), Moscow, Russian Federation; ${ }^{3}$ Biostatistics and Clinical Trials Center, Novosibirsk, Russian Federation

Background: Results from various phase 3 clinical studies have demonstrated the efficacy of canakinumab to treat patients with systemic juvenile idiopathic arthirtis (s JIA). However, limited information is available on the long-term efficacy and safety of this drug to treat children with sJIA.

Objectives: To evaluate the long-term efficacy and safety of canakinumab in patients with SJIA treated at the National Medical Research Center of Children's health, Moscow, Russia.

Methods: This was a prospective, single-center study that included canakinumab (CAN)-naive patients diagnosed with sJIA following the International League of Associations for Rheumatology (ILAR) criteria and start receiving CAN treatment from 10/2012 to 03/2016. Patients included in this study also participated, for defined periods of time, in the clinical trial NCT02296424. Patients with active disease started treatment with canakinumab $4 \mathrm{mg} / \mathrm{kg}$ A treat-to-target approach was used, canakinumab was discontinued in patients on clinical remission, either following the NCT02296424 protocol or by investigator's decision, and re-introduced in those patients who experienced a relapse afterwards. Disease characteristics and demographics were recorded at the time of diagnosis and initiation of treatment (study entry). Disease activity was evaluated periodically using the adapted JIA ACR core set measures, and percentages of patients with inactive disease and on clinical remission were calculated using the SJIA ACR criteria. Response to treatment was also evaluated by calculating modified ACR responses and JADAS-71 scores. Safety was assessed by collecting and classifying adverse events (AEs) at each visit.

Results: Nineteen patients presenting with SJIA were included in this study, with a median age at treatment initiation of 9.6 (interquartile range, IQR 6.4-11.1) years and a median disease duration of 4.4 (IQR 1.2-7.0) years. Most patients (17/19) had been treated previously with one or more biologic agents for SJIA. As of 23 December of 2019, the median time of follow up was 55.5 (47-71.7) months, with all patients being followed for at least 3.5 years and 5 patients followed for more than 7 years. As it is shown in figure 1, most patients (16/19) were on clinical remission one year after starting therapy, and this effect was sustained at year $3.5(17 / 19)$. ACR 90 responses were observed in $84.2 \%(16 / 19)$ patients at one year and $94.7 \%$ (18/19) patients at 3.5 years, whereas JADAS-71 scores decreased from 15 (14: 28.5) at baseline to 0 (0: 0 ) at one year with 4/19 patients maintained with JADAS$71>0)$; at 3.5 years, only one patient had JADAS- $71>0$ ( 0.47 , due to slight ESR increasing). Concerning the 5 patients with $>7$ years of follow up, three of them were in clinical remission for more than 3 years, including one who had discontinued therapy more than 2 years. Another patient had a relapse after attempting drug discontinuation, but recovered clinical remission after reintroducing canakinumab, and remained in this state for the last two years. The remaining patient has persistent low levels of disease activity during the last four years of follow up. AEs required hospitalization were reported in $36.8 \%(7 / 19)$ patients.

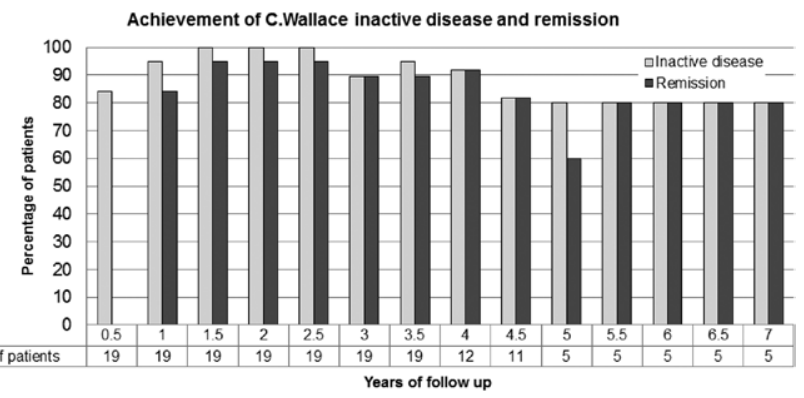

